SINTFSE - REV. DE FII OSOFIA

V. 27 N. 88 (2000): 199-211

\title{
INTUIÇÃO INTELECTUAL EM \\ SCHELLING: \\ PERSPECTIVAS PRÁTICAS
}

Paulo Sérgio de Jesus Costa

Resumo: O conceito schellingeano de intuição intelectual exerce um papel fundamental em sua filosofia. A intuição intelectual requer, entretanto, o contexto da filosofia prática para ser compreendida em todas as suas implicações. Tal intuição intelectual funciona em uma ética não proposicional. O idealismo do jovem Schelling constitui, na verdade, uma ética prática.

Palavras-chave: Intuição intelectual, Filosofia prática, Idealismo, Shelling.

Abstract: The Schelling's concept of intellectual intuition plays a fundamental role in his philosophy. However, intellectual intuition requires the context of practical philosophy in order to be understood in all its consequences. Such intellectual intuition works in a non propositional ethics. The Schelling's early idealism is in fact a practical ethics.

Key words: Intellectual insight, Pratical philosophy, Idealism, Schelling. 

interdição kantiana da intuição intelectual, floresceu um forte impulso de renovação do papel dessa importante noção. Entre os paradigmas do trabalho filosófico é possivel, sem dúvida, apontar a intuição como central para algumas orientações ${ }^{1}$. Na história do idealismo alemão, a incorporação da intuição intelectual se deu em especial por Fichte e Schelling ${ }^{2}$. Em Schelling, sobretudo, percebe-se uma forte tensão na compreensão da intuição intelectual. Uma fertilidade inesperada, capaz de estimular desenvolvimentos que nos surpreendem na tradição idealista alemà.

Nos primeiros escritos do filósofo, o contexto da discussão exibe uma oscilação entre o caráter "transcedental" e a afirmação "ontológica" do mundo. Como resultado da assimilação crítica de Schelling, na aproximação das posiçōes crítica (Kant e Fichte) e dogmática (Espinosa), assistimos a uma peculiar ampliação do sentido do intelectual. $O$ de'tenir do pensamento de Schelling não tardará, neste sentido, a vislumbrar uma filosofia da natureza como expressão do Absoluto, no movimento de uma gradativa valorização do sensivelt. A recuperação da finitude na infinitude e vice versa é condição necessária para a realização do projeto schellingeano? A ênfase ética, presente nos textos

\footnotetext{
Talvez seja possivel identificar cinco grandes paradigmas filosóficos: al dialético; b) hermenèutico; cl transcedental; d) anahitico; e el intuicionista. É claro que essa divisào é didática, nào pretendendo compartimentar de modo rígido a atividade filosófica. No caso de Schelling, por exemplo, há a combinação da dialética com a intuição, não deixando ainda de fora uma certa sensibilidade hermeneutica implicita. Num mesmo filósofo seria possivel, além disso, identificar momentos, mais ou menos característicos, onde os paradigmas se cruzam. A fenomenologia neste século, por exemplo, irá trabalhar com intuição e hermenêutica: Husserl enfatiza mais a intuição, Heidegger a hermenêtica. Bergson e Maritain irão renovar a intuição. A pragmática transcedental, de Apel e Habermas, irá lançar mão do paradigma transcedental mais o analitico, sem deixar de lado também certos elementos da hermenêutica. Vittorio Hösle, no seu idealismo objetivo, reintroduz a dialética. As recentes discussões sobre o tema, porém, pecam muitas vezes por ignorarem ènfases diferenciadas no modo de tratar o problema.

? Cf. J. Barion, Die intellektuelle Anschauung bei J.G. Fichte und Schelling.

${ }^{3}$ Cf. X. Thuette, Une philosophie en devenir. Tilliette usa a expressão "uma flosofia em devir" (Une Philosophie en Devenir), titulo de sua monumental obra sobre Schelling, no intuito de chamar a atenção para a dinámica viva do pensamento de Schelling.

${ }^{2}$ Cf. M. Maesschatck. Essai sur l'anthropologie shellingienne. Para um aporte antropológico ao tema. O autor afirma: "A evoluçāo da antropologia schellingeana nos parece particularmente significativa, na medida em que ela passa de um tratamento negativo (grifo do autor) das condiçōes de sobrevivência do Eu empírico à constituiçào progressiva da pessoa como ser de relaçāo, de acolhimento" (p. 475).

s Cf. J. Schlanger, Schelling et la Réalité Finie. Estuda-se nessa obra a questão colocada por Schelling acerca de uma filosofia que recupera a realidade integralmente. A autora diz a respeito do seu trabalho: "O problema deste estudo é aquele da conexào estreita de dois temas em Schelling: o tema de uma filosofia concreta, que recupera integralmente a intuiçăo, e o tema da simultaneidade do
} 
de Fichte, é renovada por Schelling, mediante um espírito espinosano. Schelling pretendeu desenvolver uma "Ethik à la Espinosa" intuição intelectual funciona primordialmente no âmbito de uma filosofia da praxis.

O que vai qualificar em Schelling essa significativa figura do pensamento filosófico e romântico da época, a intuição intelectual, é uma decisiva orientação prática ${ }^{7}$, não meramente transcedental (como em Kant e Fichte). A incondicionalidade intuída intelectualmente como Eu absoluto, como fundamento (Grund) para além da transcedentalidade e da objetividade, pressupõe uma certa capacidade de des-reificação : a supressão da relação cognitiva sujeito-objeto . A conseqüência imediata é que o incondicionado não poderá ser realizado na esfera teórica, pois estando para além da relação sujeito-objeto, não pode ser apreendido no mundo do saber. Logo, a intuição intelectual desencadeará o rastro de um esforço (Strebent) de realização prática do incondicionado, como exigência fundamental para um Eu empírico que deseja romper os limites da condicionalidade. Todo o desenvolvimento posterior da filosofia schellingeana, além disso, será tributário dos aspectos existenciais potenciais, sugeridos pela "faculdade misteriosa e maravilhosa" da intuição intelectual". Em todas as suas transformações subseqüen-

absoluto e do finito em uma realidade constituída por totalidades discretas", p. 1. E não é por acaso que será objeto de estudo precisamente as filosofias da natureza e da identidade, porquanto se apresenta amadurecido no pensamento de Schelling a importância filosófica da vida e da experiência, não mediatizadas exclusivamente por conceitos. $O$ que interessa ao nosso estudo é ressaltar que desde o início a orientação schellingeana apresenta importantes elementos que sugerem os desenvolvimentos da filosofia da natureza e os temas posteriores. Em especial, o conceito de intuição intelectual reúne entonações que possibilitam um acurado registro hermenêutico que prefigura a invasão do infinito no finito ao longo do intinerário filosófico schellingeano.

"Cf. A. PIper, „Ethik À La Spinosa", Historisch-systematische Überlegungen zu einem Vorhaben des jungen Schelling.

${ }^{7}$ Cf. M. Frank, "Intellektuale Anschauung“, Drei Sttellungnahmen zu einem Deutungsversuch von Selbstbewußtsein: Kant, Fichte, Hölderlin/Novalis. A noção de intuição intelectual ocupou um lugar central também no movimento romântico. A celebração do en kai pan (um e todo), via intuição intelectual, atingiu todo o mundo culto da época. Schelling irá trilhar um caminho próprio, malgrado as relações estreitas durante algum tempo entre o filósofo e os maiores românticos do período.

${ }^{8}$ F. W. J. Schelling, Briefe, Achter Brief, 203-204.

${ }^{9}$ Cf. L. HunH, Fichte und Schelling, Oder: Über die Grenze menschlichen Wissens. Os limites do saber humano são tematizados na obra de Schelling particularmente por dois conceitos: a intuição intelectual (intellektuelle Anschauung) e a noção de êxtase (Ekstasis). Schelling sem dúvida irá minimizar o papel da intuição intelectual a partir da filosofia da liberdade de 1809. Nas liçōes de Munique sobre a história da filosofia moderna (Vorlesungen Zur Geschichte der neuren Philosophie) (1827), embora Schelling defenda a noção perante a crítica de Hegel, não parece conferir à intuição intelectual mais do que um papel regulador. $O$ conceito de êxtase, entretanto, que substituirá a intuição intelectual 
tes, a filosofia de Schelling deve muito às "virtualidades" práticas resultantes do seu conceito inicial de intuição intelectual ${ }^{\prime \prime}$. A exigência não discursiva da intuição intelectual transferida do plano triunfante da relação com o absoluto tornar-se-á a atmosfera constitutiva do universo filosófico no acolhimento da totalidade ${ }^{n}$.

\section{A trajetória filosófica do jovem Schelling: uma filosofia prática.}

Quando percorremos os primeiros escritos de Schelling, temos a sensação clara de um pensador plasmando seu próprio pensamento, malgrado o uso de uma terminologia alheia. Não que não haja afinidade profunda, própria do espírito (Geist), como diriam os alemães, de uma época. Schelling participa de um mundo repleto de dramáticas experiências históricas, a começar pela revolução francesa. Vive o entusiasmo do dia no tocante a uma humanidade renovada, liberta e doravante construindo um novo ethos. As inflexões, portanto, das suas opções filosóficas juvenis não ultrapassaram aquela preocupação com a liberdade que permeava a emergência da Weltanschlaulung moderna, poderosamente sintetizada no slogan da revolução francesa: liberdade, igualdade, fraternidade ${ }^{12}$.

mais tarde, nas Liçōes de Erlangen (Initia Philosophiae universae, Erlanger Vorlesungen) (1820-1821), no fundo pode ser visto como uma radicalização de alguns elementos aporéticos já presentes desde o inicio na conceitualização daquela primeira noçăo. A contrapartida dessa passagem da intuiçào intelectual para o êxtase, é a valorização positiva do mundo. Daí a conclusão: a intuiçào intelectual acaba por conduzir ao elemento positivo, àquilo que Schelling denominou de passagem da filosofia negativa para a filosofia positiva.

"A partir do idealismo prático do jovem Schelling, filosofia caracterizada por uma forte ênfase histórica na autonomia, os conteúdos concretos tais como a natureza, a arte, a história, a mitologia, a religião vāo sendo integrados mediante a valorização cada vez mais intensa da idéia de imediatidade (Unmittelbarkeit), uma das marcas da concepçāo de intuição intelectual. É como se a exigência de imediatidade, própria da intuição intelectual do Absoluto, suscitasse no plano fenomênico o cuidado na preservaça da integridade daqueles conteúdos experienciais finitos. Em outros palavras, trata-se de não falsificar a realidade com abstraçôes conceituais artificiais.

i) Num certo sentido, a fenomenologia e a hermeneutica procuraram dar continuidade a este projeto no presente século. Schelling também pode ser encarado como um filósofo que prefigurou o existencialismo, assim como vários aspectos da teoria crítica. Uma discussão dessas afinidades, todavia, está fora do escopo deste estudo.

1. Cf. D. Henkich, The French Revolution and Clasical German Philosophy: toward a determination of their relation, in Asthetic Judgment and the moral image of the world, Studies in Kant. 
O espírito do tempo está particularmente presente em um famoso fragmento, atribuído a Schelling num primeiro momento ${ }^{13}$, onde um "programa" estabelece as metas indeclináveis do idealismo nascente. Tratase do assim chamado o mais antigo "Programa de Sistema" (Systemprogramm) do idealismo alemão ${ }^{14}$. A visada ética desse "panfleto" não deixa de ecoar motivos kantianos. Essa preocupação reflete o interesse pela razão prática que vai mais e mais manifestando sua primazia ao longo dos textos vindouros. O despertar precoce de Schelling para a filosofia foi motivado pela necessidade de produzir uma filosofia que fosse expressão da idéia de liberdade:

"...uma ética. Como a metafisica inteira no futuro desemboca na moral (Kant com seus dois postulados práticos deu apenas um exemplo disso, não esgotou nada), essa ética não será outra senão um sistema completo de todas as ldéias ou, o que é o mesmo, de todos os postulados práticos. A primeira ldéia é naturalmente a representação de mim mesmo como um ser absolutamente livre" 15.

Em outro momento, Schelling afirma:

"O começo e o fin de toda a filosofia é a liberdade" 16.

A centralidade da idéia de liberdade é fruto da inquietação ética no cerne de uma filosofia que não se contenta com a mera capacidade teórica. Eis uma das contribuições mais relevantes da filosofia schellingeana ${ }^{17}$. Uma expansão da idéia de liberdade atravessa toda a

\footnotetext{
13 Depois do descobrimento e da publicação do fragmento, por Franz Rosenzweig em 1917, onde a autoria é conferida a Schelling, uma sucessão de disputas reclamam a paternidade do texto para outros autores. Entre os autores cogitados, encontram-se Hölderlin e, mais recentemente, Hegel.

${ }^{14}$ Cf. M. Frank e G. Kurz, Materialien zu Schellings philosophischen Anfängen, 110. O lugar estratégico desse texto está menos na esfera da elucidação conceitual do que nas sugestões hermenêuticas relevantes para uma aproximação conseqüente ao conceito de intuição intelectual schellingeano.

${ }^{15}$ Ibidem, 110

${ }^{16}$ F. W. J. Schelling, Vom Ich, \& VI, 37-39.

${ }^{17}$ Cf. M. VETo, La primauté du pratique selon Schelling, 221-222. O autor comenta que Schelling fora sempre acusado: "de ter negligenciado a prática, desconhecendo a importância filosófica dos problemas morais, políticos e sociais". É verdade que "contrariamente a Kant e a Fichte, Schelling jamais escreveu um tratado de ética". Vetö recusa, todavia, a tese de que Schelling não tenha se ocupado com ética: "mesmo que ele [Schelling] tenha restringido sua especulação em uma esfera propriamente metafísica, não abordando verdadeiramente a atividade concreta dos humanos, ele não cessa de meditar e de expor em uma forma nova e profunda a relação entre o teórico e o prático". Talvez, quem sabe, a grande contribuição de Schelling tenha sido justamente renunciar ao tratamento da ética, justamente porque era sua preocupaçăo mais fundamental. A tese que vamos defender, assim, é a de que o idealismo do jovem Schelling é, na verdade, uma ética não discursiva. A ausência de tratados não é por si só sinal de que o tema está ausente de sua agenda filosófica. Seria o mesmo que afirmar que Wittgenstein não se preocupou com ética porque quase não escreveu sobre o tema.
} 
trajetória filosófica de Schelling ${ }^{18}$. É uma aporia nos primeiros escritos schellingeanos (1794-1796) ${ }^{19}$ que cria as condições da realização prática, envolvendo problemas éticos, sociais e jurídicos ${ }^{20}$. A intuição intelectual definida por Schelling no sentido de uma cesura tempora, um corte no tempo descondicionador, é a força que irá remeter ao esforço (Streben) da praxis. A inexistência de tratados de fôlego explícitos sobre temas essenciais à filosofia prática advém da dificuldade inerente à razão discursiva de operar no âmbito da ação ${ }^{21}$.

\section{O papel da intuição intelectual em uma "Ethik à la Spinoza".}

O projeto schellingeano de radicalização do criticismo kantiano acabou conduzindo a uma "Ethik à la Spinozd"22. Esse processo implicou na

is Cf. J. Bracken, Freiheit und Kausalität bei Schelling, 10. Para Bracken, o problema da liberdade perpassa todo o pensamento schellingeano, assumindo diversas formas. Sua tese é que a partir de 1809 , entretanto, uma certa compreensão da liberdade permanece constante até o final de sua carreira filosófica. Sem entrar no mérito da tese do autor, é possível sugerir que o jovem Schelling concebe a liberdade num contexto ético-prático, não discursivo.

${ }_{19}$ Temos em vista principalmente os seguintes escritos: Do Eu como princípio da Filosofia ou sobre o Incondicionado no Saber Humano (Vom Ich als Princip der Philosophie oder Uber das Unbedingte im Menschlichen Wissen, 1795) e Cartas Filosóficas sobre Dogmatismo e Criticismo (Philosophische Briefe über Dogmatismus und Kriticismus, 1795).

${ }^{2}$ Cf. C. IBer, Das Andere der Vernunft als ihr Prinzip, 6. Segundo Iber, a aporia do primeiro programa filosófico schellingeano está na transformação de um princípio absoluto primariamente ontológico em um princípio absoluto teórico subjetivo. Ele afirma antes: "O programa ele mesmo é contraditório" (p. 5). Pois bem, a contradição do programa schellingeano é precisamente o que tornará a filosofia prática interessante em Schelling.

${ }_{21}$ Cf. C. Gómez, El idealismo del joven Schelling: una filosofia de la acción, 131.

Gómez sustenta: "O idealismo do jovem Schelling, mais do que uma teoria do conhecimento, se inscreve efetivamente naquilo que se pode interpretar como uma filosofia ética". Em outro momento, o artigo de Gómez dá a entender que a intuição intelectual tem um fim a ser alcançado: "O filósofo deve agora empenhar-se na consecução daquele fim que, antecipado de alguma maneira ao modo de uma intuição intelectual, se experimenta por sua vez como fundamento próprio e perfeição ainda por alcançar" (p. 132). Haveria uma relação intrinseca entre temporalidade e intuição intelectual. A mais evidente objeção a ser feita é que posso assim ficar sem critérios objetivos para caraterizar uma ação ética. Como poderia distinguir então as minhas escolhas da posição meramente pragmática? Creio que nesse ponto, Schelling não pode dar respostas. Seria, nessa perspectiva, importante introduzir uma discussão sobre os direitos humanos, julgamentos de valor etc. Provavelmente aí reside o maior problema de uma ética não discursiva. Tudo indica que ela pressupõe a capacidade de escolher corretamente uma ação sem o concurso de nenhum princípio material explícito. ${ }^{22}$ Cf. F. W. J. Schelling, em uma carta a Hegel, 6 de janeiro de 1795: "Trabalho agora em uma Ethik à la Spinosa - ela deve estabelecer os supremos princípios 
ontologização da filosofia transcedental. No bojo das transformaçōes fundamentais imprimidas à filosofia kantiana está a mudança de rumo na interpretação do Eu fichteano. Enquanto que para Fichte o Eu é a atividade de uma estrutura transcedental, necessariamente posto pela intuição intelectual, experiência onde o sujeito não se distingue do objeto, para Schelling o Eu adquire uma dimensão ontológica.

O texto onde essa transformação se deu, "Do Eu como Princípio da Filosofia ou sobre o Incondicionado no Saber Humano", é também o lugar onde aparece pela primeira vez o conceito de intuiçăo intelectual. A originalidade de Schelling reside na afirmação de que tal intuição do Eu ultrapassa toda e qualquer relação sujeito-objeto, inclusive aquela proposta por Fichte, a do Eu consigo mesmo. Resulta daí que a intuição intelectual, ganhando estatuto ontológico, vai ao mesmo tempo dar uma nova perspectiva à filosofia prática ${ }^{23}$.

A intuição intelectual apresenta as seguintes características:

- Ela é imediata (Unnittelbar). No sentido de que nenhuma medi ação é possível (conceitos, experiências cognitivas) ${ }^{24}$. Não se confundindo, porém, com a intuição sensível.

- Implica a superação da relação sujeito-objeto ${ }^{25}$.

- Permite ao Eu finito a presença em si do incondicionado, da liberdade absoluta ${ }^{26}$.

Para Schelling, a filosofia tem que partir do incondicionado. Somente a intuição intelectual pode trazer para a "finitude" o incondicionado. O que fica patente nessa atribuição schellingeana é o fato polêmico de que nenhum sistema teórico pode satisfazer. Começa a emergir a desconfiança de que há uma incompatibilidade radical entre o incondicionado e o saber humano. Tanto o criticismo como o dogmatismo parecem conduzir a falsificações do incondicionado, não obstante as suas declaradas aspirações. Ambos os sistemas são insuficientes, pois trabalham apenas a partir da oposição entre objeto (nãoEu) e sujeito $(\mathrm{Eu})^{27}$. Sanar essa impossibilidade é suposto pela intuição intelectual.

de toda a filosofia, nos quais a razāo teórica e prática se unificam" (Plitt, I, p. 74), citado em IBER, op. cit., 32.

23 No trabalho de Schelling anterior. "Sobre a Possibilidade de uma Forma de Filosofia em Geral" (Über die Möglichkeit einer Form der Philosophie überhaupt, 1794), a ênfase recai fortemente na filosofia teórica, malgrado já se poder detectar uma preocupação ontológica de fundo.

24 Cf. F. W. J. Schelling, Vom lch, § VIII, 48-50.

${ }^{25}$ Ibidem.

${ }^{26}$ Ibidem, \$ VIII, 41-43.

${ }^{27}$ Cf. A. PIPER, op. cit., 549. 
O sucesso depende de uma faculdade capaz de deixar a esfera dos objetos, realizando a incondicionalidade. Numa perspectiva que pede tanto, isto é, o ponto de vista sub specie aeternitatis, é natural que as dificuldades despontem logo. O projeto teórico logo manifesta sinais de insuficiência. Uma certa dialética trágica vai instaurar uma série de novos desenvolvimentos. O destino de Schelling vai ser lidar com os sucessivos pontos de partida. Percebe-se uma mistura de tempo e eternidade movendo o pensamento na vereda schellingeana.

A aporia fundamental levantada pelo "Do Eu" é a impossibilidade de explicar a passagem da realidade absoluta para a condicionada. Isso fica visível na maneira de conceber a intuição intelectual. Um caminho diferente será trilhado no outro sentido, isto é, trata-se de a partir da realidade finita chegar ao Absoluto como meta. O ponto de vista do Absoluto deve ser substituído pelo da finitude. É nesse ponto que a vida prática se apresenta como uma possibilidade da filosofia teórica em não se perder em meras abstraçōes ${ }^{2 x}$. Esta será a tarefa do próximo texto de Schelling: "Cartas Filosóficas sobre Dogmatismo e Criticismo".

\section{Intuição intelectual e filosofia prática.}

A intuição intelectual, tal como foi considerada até então, guarda uma "virtualidade" que irá manifestar-se logo na trajetória filosófica schellingeana. Trata-se de uma latente inserção da natureza e do Eu finito na realização do Absoluto ${ }^{29}$. Paradoxalmente, a exigência de incondicionalidade acaba por abraçar a realidade sensível. É aí que a possibilidade de realização prática entra em cena, pois uma certa dignidade ontológica é conferida ao mundo da finitude. O caráter aporético

\footnotetext{
${ }^{2 k}$ Cf. F. W. J. Schelling, Antikritik (1796). Trata-se de uma recensão de Schelling sobre sua obra "Do Eu". Lá lemos: "A filosofia que é uma mera idéia, cuja realização o filósofo só pode esperar da razão prática, segue sendo incompreensível e até mesmo ridícula, enquanto não aprender de Kant que as idéias não têm que ser objeto de ociosas especulações, e sim da ação livre. Que todo o reino das idéias só tem realidade para a atividade moral do homem. Que ao homem não é permitido encontrar objetos, alí onde ele memso começa a criar e a realizar" (pp. 1407-1408).

2.! Cf. X. Tillette, L'Absolu et la philosophie, 75. O autor sugere que a ruptura entre o sensível e o intelectual será amortizada nas "Cartas", culminando na filosofia da natureza. De fato, visto que pode haver no Eu finito a intuição do Eu absoluto, então não pode existir uma total heterogeneidade entre ambos. Haveria, portanto, como já afirmado, uma crescente absorção do sensível no plano do Absoluto.
} 
da "Ethik à la Spinosa" revelará a imanência do Absoluto no mundo, malgrado sua absoluta transcendência.

As "Cartas"30 vão levantar de maneira bem aguda as dificuldades e aporias oriundas do texto "Do Eu". A equivalência dos dois principais sistemas, dogmatismo e criticismo ${ }^{31}$ deverá instaurar uma nova via de aproximação menos triunfal para o incondicionado. Uma mudança de registro no modo de compreender a intuição intelectual acompanha Schelling, nesse aprofundamento das dificuldades que sua filosofia ensejou.

O conceito inicial de intuição intelectual pautava-se pela referência a Kant e a Fichte. Espinosa passa agora a primeiro plano. Isso parece indicar que o caráter ativo da intuição intelectual em Fichte, em virtude da virada ontológica sofrida, necessita de uma compensação paralela. O amor Dei intelectualis de Espinosa inverte nesse contexto a ênfase interpretativa. Qualidades ontológicas são aproximadas da compreensão transcedental, no sentido de lograr uma unificação na maneira de considerar a intuição intelectual. Aquilo que antes era pura atividade, em Fichte vira contemplação. A fusão de ambas, atividade e contemplação, acarreta algumas conseqüências notáveis.

As novas notas que a intuição intelectual vai ganhar são tipicamente do reino da praxis:

"Contudo, mesmo para aqueles que não possue'me e'ssa libordade da intuição de si, hâ pelo me'nos uma aproximağno dela, experiências metiatas pelas quais ela deixn pressentir sua existência" 32.

A tolerância em relação à finitude, face àquela experiência olímpica da intuição intelectual, perdida em serena contemplação do incondicionado além do tempo, começa a anunciar caminhos outros, mais humanos.

Schelling continua:

"Também uma estética perfeita ctomada esta palazra no sentido antigo) estabelecerá açós empiricas, que só são explicáveis como imitnçōes daquela ação intelectual e absolutamente não seriam concebizeis se não tivéssemos alguma vez - para exprimir-me com a linguagem de Platão - intuido no mundo intelectual seu modelo" 33 .

\footnotetext{
${ }^{30}$ A tradução portuguesa aqui utilizada é de Rubens Rodrigues Torres Filho. ${ }^{31}$ Cf. B. SANDKAUlen-Bock, Ausgang vom Unbedingten. A autora trabalha com a hipótese de que essa dificuldade é constitutiva no programa filosófico schellingeano, onde se exige que a filosofia parta do incondicionado. Schelling estaria seguindo Jacobi em tal exigência. O ponto é que a razão discursiva mostra-se sempre incapaz quando se trata do incondicionado. A conclusão é uma sucessão de aporias.

32 Cf, F. W. J. Schelling, Briefe, Achter, 203-204.

2.3 Ibidem, 203-204.
} 
A ação encontra seu lugar concreto. O esforço (Streben) ganha em importância na esfera da finitude. Não deveriamos lamentar, pois o empenho ético sério é a única forma possível de realizar uma experiência do Absoluto no tempo.

A decepção teórica não choca Schelling, pelo simples fato de que o que realmente importa é a realização prática da liberdade. Em afinidade com tal postura, há um elogio do cético:

"Como tem infinitamente mais mérito para a verdadeira filosofia o cético que, de antenão, declara guerra a todo o sistema universalmente válido. Como tem infinitamente mais mérito do que o dogmaticista, que quer, de agora em diante, que todos os espiritos prestem juramento ao simbolo de uma ciência teórica. Enquanto aquele permanece dentro de seus limites, isto é, enquanto cle mesmo não ameaça intervir no domínio da liberdade humana, enquanto acredita na verdade infinita, mas também somente em seu gozo infinito, na verdade progressiva, construida por si mesma, conquistada por si mesma, quem não honraria nele o autêntico filósofo?" 34

Um outro aspecto da "reconciliação" prática schellingeana se daria no campo da arte. As cartas primeira e décima parecem ver na tragédia uma possibilidade de suprir esteticamente a impossibilidade teórica de uma experiência do incondicionado:

"Eu o entendo, meu caro amigo! Parece-lhe mais grandioso lutar contra uma potência absoluta e sucumbir lutando, do que garantir-se previamente contra todo o perigo, através de um Deus moral" ${ }^{35}$.

A relação da praxis com a tragédia poderia gerar outra dificuldade. Afinal, para agir serenamente não podemos estar em estado trágico o tempo todo. Schelling, entretanto, considera uma alternativa ao significado da tragédia:

"Se o espetáculo da luta destina-se' a expor o homem no momento supremo de sua potência autônoma, a calma intuiģão daquele repouso o encontra, inversamente, no momento supremo da vida" 36.

É curioso que a solução pacífica remete a um dos aspectos da intuição intelectual, quando objetivada:

"Foi essa intuiģão de si mesmo que Espinosa objetivou. Enquanto intuía em si o intelectual, o Absoluto não era mais, para ele objeto ${ }^{\prime 37}$.

"Ele se iludia ao acreditar nisso" 38 . "Mas aquele pensamento - de estar

${ }^{34}$ Cf. F. W. J. Schelding, Briefe, Fünfter, 184-187.

${ }^{35}$ Ibidem, Erster, 178-179.

${ }^{36}$ Ibidem.

${ }^{37}$ Ibidem, Achter, 204-205.

38 Ibidem. 
dissolvido no objeto absoluto - era suportável para ele, justamente por haver surgido de uma ilusão, e ainda mais suportável por essa ilusão ser indestrutivel" 39 .

Em outras palavras, a serenidade da dissolução no Absoluto é uma ilusão indestrutível. Se é assim, a praxis, a tragédia e a serenidade constituem três modalidades da razão prática em Schelling. Nesse ponto, Schelling discorda do seu grande amigo Hölderlin ${ }^{40}$. Sem afastar a experiência estética, enquanto parte relevante da filosofia prática, devemos observar que não há em Schelling a exclusão da praxis, nem daqueles aspectos contemplativos da intuição intelectual. A realidade é integralmente acolhida nessa perspectiva. E fica evidente que a capacidade individual de cada um fazer frente às dificuldades de toda a ordem no mundo, depende em última instância da relação intransferível que cada um mantém com a liberdade absoluta ou o incondicionado.

Um último aspecto da intuição intelectual no mundo prático é a filosofia da natureza. O próximo desdobramento da recuperação da realidade será a natureza. A defesa da vida também aí se verificará. Schelling escreve na introdução da obra "Idéias para uma Filosofia da Natureza":

"A mera espéculaçño é uma doeņa do espírito do homem" +1 .

A importância do passo de Schelling, no âmbito da filosofia da natureza, trará inegáveis benefícios para uma ética do meio ambiente hoje. Esse tema, todavia, ultrapassa o propósito da presente investigação.

Em torno de uma possível conclusão, poderíamos dizer que a intuição intelectual percorreu um longo caminho nos escritos do jovem Schelling. Relacionada com a pura incondicionalidade, acabou por recuperar a realidade finita. A importância desse fato é de grande alcance, pois nos ensinou a acolher a finitude, sem perder de vista o Absoluto. Estímulo para a filosofia prática, a intuição intelectual naturalmente coloca em questão uma racionalidade que queira confinar-se apenas a procedimentos demonstrativos. É muito provável que seja impossível realizar qualquer coisa na vida, sem a faculdade da intuição. Permanece, con-

39 Cf. F. W. J. Schelling, Briefe, Achter, 204-205.

${ }^{40}$ Cf. C. Iber, op. cit., 43-44. O autor chama a atenção para o fato de que em Hölderlin a arte é o único lugar de apresentação do Absoluto, não acontecendo o mesmo com Schelling. É possível, como Iber reconhece, que a primeira e a décima carta tenham tido a influência de Hölderlin, todavia, permanece para Schelling a convicção que ao lado da arte (tragédia) está a praxis. E se há praxis, então é necessário aquela ilusão indestrutível da serenidade, à qual referimos acima.

${ }^{41}$ Cf. F. W. J. Schelling, citado por Schmien-KowARzIK em: „Von der wirklichen, von der seynden Natur", Schellings Ringen um eine Naturphilosophie in Auseinandersetzung mit Kant, Fichte und Hegel, p. 24. O autor relaciona além disso, a intuição intelectual da oitava carta com a filosofia da natureza, ressaltando a relação intrínseca da filosofia da natureza com a filosofia prática. 
tudo, o desafio de não assumir ingenuamente essa "ilusão indestrutível" da intuição intelectual. Em todo caso, a filosofia continua aberta a experiências criativas, especialmente, no âmbito da ética. Oxalá este breve estudo possa lançar um grão de areia na imensa tarefa.

\section{Referênias Bibliográficas}

BARION, J. Die intellektuelle Anschauung bei J. Fichte und Schelling. Diss. Bonn, 1929.

BRACKEN, J. Freiheit und Kausalität bei Schelling. Freiburg/München: Karl Alber, 1972.

FRANK, M. e KURZ, G. Materialien zu Schellings philosophischen Anfängen. Frankfurt (M): Suhrkamp, 1975.

FRANK, M. „Intetellektuale Anschauung“. Drei Stellungnahmen zu einem Deutungsversuch von Selbstbewußtsein: Kant, Fichte, Hölderlin/ Novalis. In: Die Aktualität der Frühromantik. Eds. Ernst Behler e Jochen Hörisch, München: Ferdinand Schöningh, 1987, 96-126.

GÓMEZ, C. El idealismo del joven Schelling: una filosofía de la acción. Pensamiento v. 50 n. 196 (1994): 131-141.

HENRICH, D. The French Revolution and Classical German Philosophy: toward a Determination of Their Relation. In: Asthetic Julgament and the moral image of the world. Studies in Kant. Stanford University Press, 1992.

HÜNH, L. Fichte und Schelling. Oder: Über die Grenze menschlichen Wissens. Stuttgart: J. B. Metzler, 1994.

IBER. C. Das Andere der Vernunft als ihr Prinzip. Berlin: Walter de Gruyeter, 1994.

MAESSCHALCK, M. Essai sur l'anthropologie schellingienne. Revue Philosophique de Louvain tome 85, n. 68 (Nov. 1987): 475-497.

PIPER, A. „Ethik À La Spinoza“ Historisch-systematische Überlegungen zu einem Vorhaben des jungen Schelling. Zeitschrift für philosophische Forschung 31 (1977): 545-564.

SANDKAULEN-BOCK. Ausgang vom Unbedingten. Göttingen: Vandenhoeck \& Ruprecht, 1990. 
SCHELLING, F. W. J. Über die Möglichkeit einer Form der Philosophie überhaupt. In: IDEM. Historisch-Kritische Ausgabe. Editores: W. Jacobs, J. Jantzen e W. Schieche. Stuttgart: Fromann-Holzboog, 1976. (Reihe I: Werke; Werke 1).

Vom Ich als Prinzip der Philosophie oder Über das Unbedingte im Menschlichen Wissen. In: IDEM. Historisch-Kritische Ausgabe. Editores: H. Baumgarten, W. Jacobs, H. Krings e H. Zeltner. Stuttgart: Fromann-Holzboog, 1980. (Reihe I: Werke; Werke 2).

Antikritik. In: Idem. Historisch-Kritische Ausgabe. Editores: H. Baumgarten, W. Jacobs, H. Krings e H. Zeltner. Stuttgart: FromannHolzboog, 1982. (Reihe I: Werke; Werke 3).

Philosophische Briefe über Dogmatismus und Kriticismus. In: IDEM. Historisch-Kritische Ausgabe. Editores: H. Baumgarten, W. Jacobs, H. Krings e H. Zeltner. Stuttgart: Fromann-Holzboog, 1982. (Reihe I: Werke; Werke 3).

SCHLANGER, J. Schelling et la réalité finie. Paris: Press Universitaires de France, 1966.

SCHMIED-KOWARZIK, W. "Von der wirklichen, von der seyenden Natur", Schellings Ringen um eine Naturphilosophie in Auseinandersetzung mit Kant, Fichte und Hegel. Stuttgart: Friedrich Frommann Verlag- Günther Holzboog, 1996.

TILLIETTE, X. Une philosophie en devenir. 2 vs. Paris: J. Vrin, 1969. L'Absolu et la philosophie. Essais sur Schelling. Paris: Presses Universitaires de France, 1987.

VETÖ, M. La primauté du pratique selon Schelling. Les Études Philosophiques 2 (Avril-Juin 1974): 221-244.

Endereço do Autor:

UFMG: Faculdade de Filosofia

Av. Antonio Carlos, 6627

31270-010 Belo Horizonte - MG 